\title{
Knowledge of rural women regarding health and nutrition practices in Bikaner district of Rajasthan, India
}

\author{
Suchitra* and Neena Sareen ${ }^{1}$ \\ Extension Education, Vivekananda Global University, Jaipur (Rajasthan) India \\ (Email: suchi3mothsara@gmail.com)
}

\begin{abstract}
The present study was conducted in Bikaner district. There are six panchayat samitis out of which Bikaner Panchayat Samiti was selected. Out of thirty one Gram Panchayat in Bikaner Panchayat Samiti four Gram Panchayat were selected namely Kilchoo Deodan, Ridmalsarpurohitan, Palana and Nalbari. One village from each selected Gram Panchayat was selected on the basis of random sampling technique. Thus, four villages were selected for the present investigation (Surdhanachauhanan, Raisar, Palana, Nalbari). A sample of one twenty rural women in the age group 15-45 years (30 rural women from each village). Interview Schedule was developed to collect the data regarding health and nutrition knowledge of rural women. The major findings of the present study revealed that in general information majority of the respondents belonged to middle age group, educated upto primary, belonged to 4001-6000/- monthly income group, nuclear family system, other backward caste, involved in agriculture occupation, had above 2.1-5 hectare of land holding, no membership of social organization, no participated in training programme and medium level of mass media contact, urban contact and extension contact. The overall knowledge of the rural women was medium. Out of eight aspects of health and nutrition the knowledge about the aspect of 'Basics of foods and nutrition' and 'Environmental hygiene' were ranked first with overall mean per cent score. On the basis of these findings it could be concluded that health and nutrition knowledge of rural women was medium.
\end{abstract}

Key Words : Health, Nutrition, Knowledge, Hygiene, Environment

View Point Article : Suchitra and Sareen, Neena (2021). Knowledge of rural women regarding health and nutrition practices in Bikaner district of Rajasthan, India. Internat. J. agric. Sci., 17 (2) : 548-557, DOI:10.15740/HAS/IJAS/17.2/548-557. Copyright@ 2021: Hind AgriHorticultural Society.

Article History : Received : 02.03.2021; Revised : 04.03.2021; Accepted : 18.03.2021

\footnotetext{
* Author for correspondence :

${ }^{1}$ EECM, SKRAU, Bikaner (Rajasthan) India
} 